\title{
Nota Técnica: \\ Alteraciones en las fábricas de piedra de la Sala Capitular del Ayuntamiento de Sevilla
}

\author{
Technical Note: \\ Alterations in the stone masonry of the Capitol Room \\ of Sevilla City Hall
}

\begin{abstract}
Recepción/Received: 4-VII-06 Aceptación/Accepted: 4-XI-06
\end{abstract}

A. Barrios Padura(*), J. Barrios Sevilla(*), L. García Navarro(**)

RESUMEN

Este trabajo ha tenido como objetivo principal determinar las causas que han originado desprendimientos de partículas y un fragmento importante de las piedras y del mortero que conforman la bóveda-artesonado de la Sala Capitular del Ayuntamiento de Sevilla. Los diferentes análisis y ensayos realizados evidencian que estas fábricas tienen un revestimiento realizado a base de pinturas al óleo sobre estuco-mortero de calcita, cuarzo, yeso y presencia de blanco de plomo con impregnación de aceite de linaza, en tanto que las fábricas de los muros no tienen revestimiento alguno. Igualmente se ha constatado el cambio de la humedad-temperatura ambiental en la bóveda, generado por la implantación de aire acondicionado y la eliminación de la ventilación cruzada natural que tenía desde su construcción. La conjunción de ambas acciones parece ser el desencadenante de las anomalías reseñadas.

Palabras clave: fábricas de piedra, revestimientos, condiciones higrotérmicas, lesiones.

\section{INTRODUCCIÓN Y OBJETIVOS}

En los últimos años se ha observado que, con frecuencia, en las edificaciones monumentales rehabilitadas se producen desprendimientos de los materiales que conforman

\section{SUMMARY}

The main aim of this work has been to determine the causes of stone loss (small particles and one larger piece) and mortar loss in the coffered vault of the Capitol Room in the City Hall of Seville. The analyses and assays carried out during the course of this research have revealed that this masonry comprises a covering of oil paints over mortar-stucco of calcite, quartz, gypsum, and lead white with linseed oil when the walls were not covered. In addition, it was confirmed that the installation of air-conditioning caused a change in the humidity and temperature in the vault, aggravated by the elimination of the cross-ventilation that the structure had since it was built. The combination of these two circumstances likely triggered the pathology in the masonry.

Keywords: stone masonry, coverings, hygrothermal conditions, damages.

(*) Universidad de Sevilla, Departamento de Construcciones Arquitectónicas I.

(**) Universidad Politécnica de Madrid, Departamento de Construcción y Vías Rurales. 
cierran, eliminándose la ventilación cruzada, y en los que se implanta una instalación de aire acondicionado.

Para analizar esta problemática, se ha realizado una investigación en la Sala Capitular del Ayuntamiento de Sevilla, con el objetivo de encontrar las causas que han originado ligeros desprendimientos en las fábricas que conforman la bóveda-artesonado de este recinto, tanto de la piedra como del mortero, así como para comprobar si estas anomalías guardan relación con los cambios de humedadtemperatura generados por el acondicionamiento de la sala tras las intervención realizada en el año 1991 (1).

\section{DESCRIPCIÓN HISTÓRICA Y COMPOSITIVA DE LA EDIFICACIÓN}

La Sala Capitular o salón de plenos es la estancia de mayor relevancia arquitectónica del conjunto monumental, sede del Ayuntamiento de Sevilla. La actual edificación es el fruto de una serie de intervenciones realizadas en los casi quinientos años de historia (2).

Hasta mediados del siglo XVI el Concejo de Sevilla tuvo su sede en unas casas de escasas proporciones, situadas en el Corral de los Olmos, a espaldas de la catedral, que compartía con el Cabildo eclesiástico. Este conjunto, que presentaba un aspecto destartalado, de arquitectura mudéjar (fábricas de ladrillo con morteros de cal), contrastaba con las nuevas construcciones renacentistas de fábricas de piedra de comienzos del siglo XVI que se correspondían con la categoría de capital del Nuevo Mundo.

La visita de Carlos V en 1526 para celebrar su matrimonio con la emperatriz Isabel fue el motivo que impulsó al cabildo a plantear la construcción de un edificio acorde con la categoría de la ciudad. Se elige para la construcción el lugar de las antiguas Pescaderías, sin uso desde el tiempo

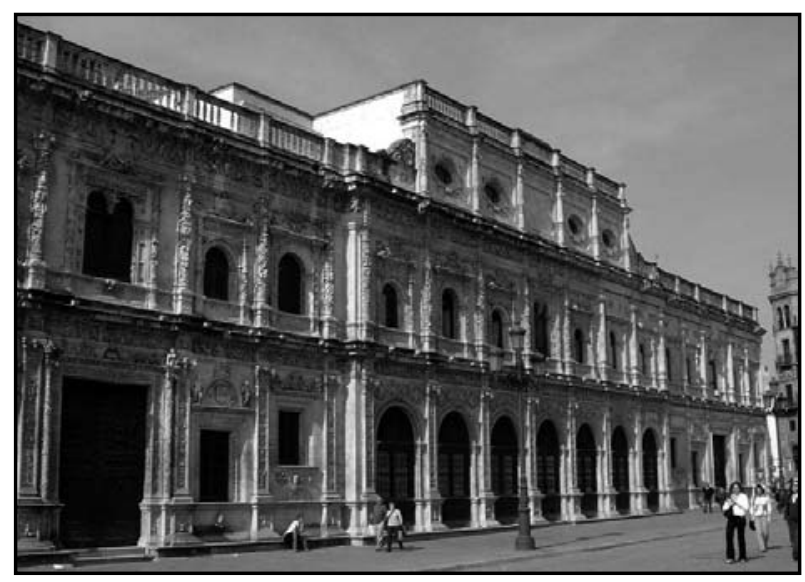

Figura 1. Ayuntamiento de Sevilla. Fachada a Plaza San Francisco. En el interior de la planta baja está situada la Sala Capitular. de los Reyes Católicos (1493). El espacio para esta construcción lindaba con el Convento de San Francisco, lo que seguramente influyó en la presencia de motivos religiosos en la ornamentación del nuevo edificio civil.

Todas las fábricas del nuevo edificio se construyeron con sillares de piedra caliza y calcarenita, traídas en su mayoría de las canteras del Puerto de Santa María, Morón de la Frontera y Utrera, tomadas con mortero de cal.

La Sala Capitular, en la actualidad salón de plenos del Consistorio Municipal, construido entre los años 15341539 , de planta rectangular $(8,27 \mathrm{~m} \times 10,94 \mathrm{~m})$, está cubierto con una bóveda casi plana de piedra de cuyos ángulos arrancan robustas nervaduras que conforman el entramado de 36 casetones con relieves esculpidos de las imágenes de los reyes de España anteriores a Felipe II, igualmente de piedra.

Los muros presentan un friso con medallones y grutescos, unas inscripciones latinas alusivas a la Justicia, imágenes heráldicas y de virtudes, un Calvario y un gran escudo de la ciudad obra del escultor Roque Balduque. Sobre una de las paredes se sitúa un lienzo representando a Santa Justa y Santa Rufina, patronas de la ciudad, que fue realizado por el pintor sevillano Juan de Espiral en 1760.

\subsection{Descripción de la bóveda-artesonado}

Para determinar el sistema constructivo empleado en la bóveda, se abrió un calo en el suelo de la sala superior, con lo que quedaba al descubierto el trasdós de los casetones 15 y 21 , y el nervio situado entre ambos.

Se comprobó la existencia de un nervio de piedra de 37 $\mathrm{cm}$ de ancho y $39,9 \mathrm{~cm}$ de canto machihembrado superiormente a los casetones, sobre el que aparece $15 \mathrm{~cm}$

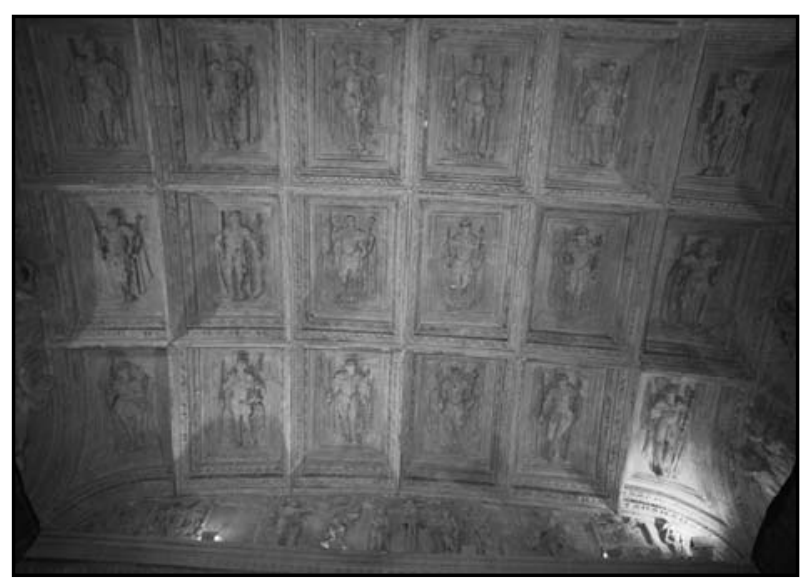

Figura 2. Detalle de los relieves con figuras de los reyes que conforman los casetones. 
de un conglomerado de piedras y mortero de cal a modo de recrecido para alcanzar la cota de los casetones.

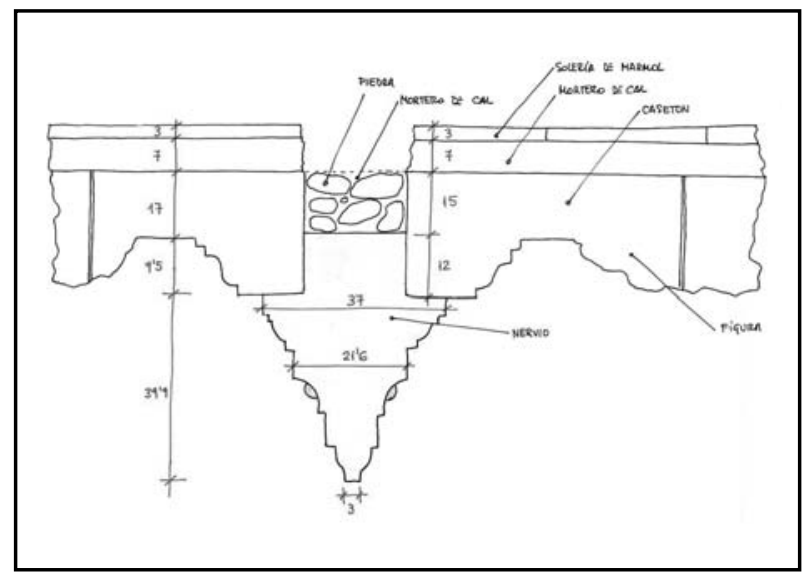

Figura 3. Detalle en sección de la bóveda-artesonado.

\section{ALTERACIONES DETECTADAS EN LAS FÁBRICAS}

En la inspección realizada se observó la presencia de una serie de anomalías que se relacionan a continuación con indicación de las ubicaciones principales y grados de afección (4 y 5):

- Desprendimiento de un fragmento de piedra del nervio 22-28, que coincide con una junta estilolítica de la piedra.

- Desprendimiento y pérdida de masa de mortero y piedras de casetones, nervios, frisos y relieves de los reyes.

- Pérdida de masa de mortero de diversas juntas de sillares con aberturas de hasta $2 \mathrm{~mm}$, así como de las piedras de los nervios y esculturas, de forma que las juntas quedan al descubierto con aberturas que en algunas casos llegan a 2,5 mm.

También se comprobó, en el examen inicial, la existencia de pátinas y recubrimientos de diferentes tonalidades tanto en la bóveda, como en los frisos.

\section{CARACTERIZACIÓN AMBIENTAL Y DE LOS MATERIALES QUE CONFORMAN EL ARTESONADO DE PIEDRA}

\subsection{Determinación de la humedad y temperatura ambiente}

Se ha efectuado un control de humedad y temperatura ambiente a diferentes alturas, mediante termohigrómetro electrónico, marca Hobo, con el fin de establecer los gradientes de estos dos parámetros (6). Las medidas se realizaron con el aire acondicionado funcionando.
La media de los valores obtenidos en tres puntos de la diagonal de la sala (extremos y central), y a intervalos de $1,00 \mathrm{~m}$ en altura, indica que hay un incremento notable de la humedad (30 a 40\%) y de la temperatura (una media del $5 \stackrel{\circ}{\circ}$ ) al pasar de la cota 0 a la $+7,00 \mathrm{~m}$.

\subsection{Determinación de sales en superficie}

Se ha procedido a la medición de contenido en sales superficiales mediante un medidor electrónico (Protimeter) que indica los índices de salinidad (no porcentajes) en una escala cualitativa calibrada de 0 a 100 unidades, por lo que la investigación sirve para establecer un estudio comparativo de los parámetros, estableciéndose la fluencia y concentración de sales por zonas, indicativa de procesos históricos de humectación-desecación con arrastre de sales solubles y su posterior cristalización, provocando de esta manera concentraciones en la superficie que denominamos "techo de sales" (7).

Los índices de salinidad en los sillares de los casetones son generalmente superiores a 60, llegando a 100 en la esquina opuesta a la entrada, en la que se han producido pequeños desprendimientos. En los sillares de los nervios analizados (banda central), los índices oscilan entre 50 y 70 excepto en los nervios que forman los casetones 27, 28, 33 y 34 , cuyos valores oscilan entre 70 y 90 . En esta zona es donde se ha producido la caída del fragmento mayor.

En el apartado 4.4.4 Recubrimientos se indican los resultados obtenidos en los diferentes análisis realizados, describiendo los compuestos que conforman estas sales.

\subsection{Medidas de humedad}

Se ha utilizado un equipo Protimeter que determina el índice de humedad del elemento (no porcentajes), por lo que los datos suministrados son cualitativos, sirviendo, en consecuencia, como datos comparativos. Las medidas se han realizado en superficie y a $4 \mathrm{~cm}$ de profundidad, para lo que se realizó el correspondiente taladro para introducir una sonda.

Los índices de humedad en superficie son de valor 0 , en tanto que en el interior oscilan entre 28 y 35 , a excepción de los puntos 1,2 y 3 de la zona $A$, que es la que más daños presenta, con valores de 46,80 y 60 .

\subsection{Caracterización físico-química de los materiales que conforman las fábricas}

\subsubsection{Metodología}

Las técnicas empleadas para el estudio de los morteros, piedras, pátinas, tratamientos superficiales $y / 0$ pinturas son $(8,9)$ : 
- Descripción macroscópica mediante lente de aumento marca Olympus SZ-PT.

- Microscopía óptica por reflexión y por transmisión, con luz polarizada. Las microfotografías obtenidas se realizaron con luz reflejada a $300 \mathrm{X}$ y con nícoles cruzados.

- Difracción de rayos X (DRX). El equipo empleado es un difractómetro SIEMENS D 500, que cuenta con un programa de identificación automática de fases que se apoya en una base de datos de minerales J CPDS con 5.760 patrones. La radiación es CuKd, monocromador de grafito, existiendo una diferencia de potencial en el tubo de $40 \mathrm{kV}$ y una intensidad de $20 \mathrm{~mA}$ en el filamento; los análisis se han realizado en el intervalo $2 \theta$ : 2-60 (10).

- Caracterización de los componentes y sus proporciones mediante análisis químico elemental de componentes mayoritarios y minoritarios.

- Caracterización física: densidad aparente y porosidad.

- Caracterización hídrica: absorción de agua, desorción al aire y capilaridad.

- Caracterización mecánica mediante ensayos a compresión (prensa multiensayos de 20 toneladas con certificado de calibración).

- Ultrasonidos con palpadores específicos de la marca Krau Kramer.

- Espectroscopía IR por transformada de Fourier, para conocer los componentes de recubrimientos o barnices. Los análisis se llevan a cabo entre $4.400 \mathrm{~cm}^{-1}$ y $370 \mathrm{~cm}^{-1}$ en pastillas de $\mathrm{KBr} 0$ mediante análisis superficial usando la técnica UATR (Universal Atenuated Total Reflectance) (11).

- Cromatografía en fase gaseosa, para la determinación de sustancias lipófilas, como aceites, secantes, resinas y ceras; y de sustancias hidrófilas, como la goma arábiga y productos afines. Las muestras se tratan con el reactivo de metilación Meth-prep II en el caso de sustancias de tipo cera u oleo-resinosas. Para los hidratos de carbono se lleva a cabo una hidrólisis y una derivatización de los monosacáridos a acetatos de alditol $(12,13)$.

- Cromatografía en fase líquida, para el análisis de aminoácidos procedentes de las capas de pintura al temple de proteína. Se emplea el sistema Pico-Tag de Waters $^{R}$ (11).

\subsubsection{Morteros}

Se han realizado una serie de análisis y ensayos en las muestras tomadas de las juntas de mortero de unión de los sillares que conforman el artesanado o bóveda de piedra (9).

En el proceso de toma de muestras e inspección de las mismas se eligieron las más representativas para realizar los análisis y ensayos previstos:
- M-1. Mortero de junta entre los casetones 18 y 19.

- M-2. Mortero de relleno entre los nervios 21 y 25 .

\section{Descripción macroscópica}

Mortero de cal con un elevado grado de descohesión interna, color blanco-crema, claramente matriz soportado y con árido silíceo bastante heterométrico (arena fina a arena gruesa) no muy abundante, y consistente en granos de cuarzo y escasos fragmentos de roca metamórfica y placas de moscovita.

\section{Difracción de Rayos-X}

Sobre esta muestra se han realizado dos difractogramas, uno sobre la muestra de mortero y otro sobre el residuo insoluble obtenido tras atacar la muestra con ácido clorhídrico.

La mineralogía de la muestra de mortero consiste en calcita $\left(\mathrm{CaCO}_{3}\right)$ como mineral mayoritario, cuarzo $\left(\mathrm{SiO}_{2}\right)$, con notables proporciones, y dolomita $\left(\mathrm{CaMg}\left(\mathrm{CO}_{3}\right)_{2}\right)$, moscovita $\left(\mathrm{KAl}_{2}\left(\mathrm{AlSi}_{3} \mathrm{O}_{10}\right)(\mathrm{OH})_{2}\right)$ y yeso $\left(\mathrm{CaSO}_{4} 2 \mathrm{H}_{2} \mathrm{O}\right)$ de manera accesoria (porcentajes inferiores al 5\%). La mineralogía del residuo insoluble en ácido $(11,12$ y 13) corresponde a cuarzo como mineral principal y moscovita y albita $\left(\mathrm{NaAlSi}_{3} \mathrm{O}_{8}\right)$ como minerales subsidiarios. El porcentaje en peso de material carbonatado atacable por el ácido es aproximadamente del $70 \%$, mientras que el del residuo insoluble es del $30 \%$.

Tabla 1. Características químicas de los morteros

\begin{tabular}{|lcc|}
\hline Compuesto & \multicolumn{2}{c|}{ Muestras } \\
& $\mathbf{1}$ & $\mathbf{2}$ \\
\hline Sílice $\left(\mathrm{SiO}_{2}\right) \%$ & 28,6 & 38,1 \\
\hline Alúmina $\left(\mathrm{Al}_{2} \mathrm{O}_{3}\right) \%$ & 0,6 & 0,7 \\
\hline Óxido férrico $\left(\mathrm{Fe}_{2} \mathrm{O}_{3}\right) \%$ & 1,3 & 1,2 \\
\hline Cal $(\mathrm{CaO}) \%$ & 38,2 & 33,1 \\
\hline Magnesio $(\mathrm{MgO}) \%$ & 0,0 & 0,0 \\
\hline Pérdida por calcinación \% & 29,9 & 26,6 \\
\hline Sulfatos $\left(\mathrm{SO}_{3}\right) \%$ & 0,94 & 0,17 \\
\hline Cloruros $(\mathrm{Cl}) \%$ & 0,17 & 0,098 \\
\hline Nitratos $\left(\mathrm{NO}_{3}\right) \%$ & 0,11 & 0,02 \\
\hline Amoniaco $\left(\mathrm{NH}_{4}\right) \%$ & 0,01 & 0,001 \\
\hline Yeso \% & 2,2 & 0,4 \\
\hline
\end{tabular}

Tabla 2. Características físicas de los morteros

\begin{tabular}{|lcc|}
\hline Muestras & $\begin{array}{c}\text { Densidad aparente } \\
\text { gr/ c.c. }\end{array}$ & Porosidad \% \\
\hline 1 & 1,43 & 34,7 \\
\hline 2 & 1,40 & 38,1 \\
\hline
\end{tabular}




\subsubsection{Piedras}

Se han tomado muestras de piedra tanto de los nervios como de los casetones en pequeños fragmentos en unos casos, y en donde se ha podido se han extraído probetas testigo de $\varnothing 5 \times 10 \mathrm{~cm}$ de altura:

- P-1. Piedra nervio entre casetones 22-28 (en este nervio se desprendió el fragmento que se menciona en el apartado 3).

- P-2. Nervio casetón 6 de la zona A.

- P-3. Casetón 33, parte inferior de la figura de D. a J uana la Loca.

- P-4. Piedra nervio 35-36.

Estas muestras se han sometido a los siguientes análisis y ensayos $(9,10,11)$ :

\section{Descripción macroscópica}

Piedra de color blanco crema, muy disgregable, deleznable al tacto y con una composición mixta carbonatadasilícea.

\section{Descripción microscópica}

Petrográficamente se trata de una roca carbonatada de grano fino constituida esencialmente por fragmentos de bioclastos de tamaño dominante y arena fina (125-250 $\mu \mathrm{m})$.

Más concretamente los fragmentos diferenciados son (Figuras $4 a$ y $4 b$ ):

- Los foraminíferos son los bioclastos dominantes (50\%) predominando los foraminíferos planctónicos redondeados con textura radial (globorotálidos) y ornamentación

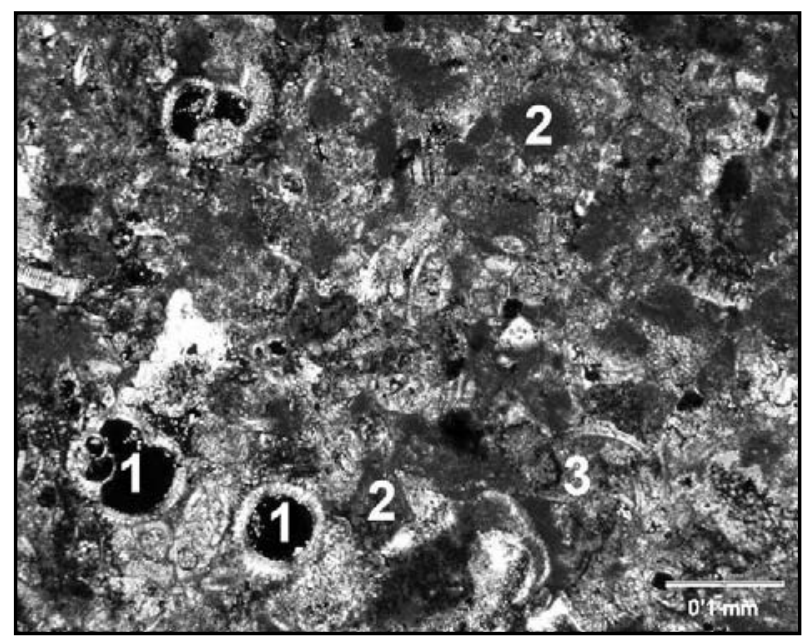

Figura 4a. Aspecto microscópico general donde se observan foraminíferos de distintos tipos (1) y peloides micríticos (2), en muchos casos fragmentados entre restos micríticos dispersos (3). bien conservada. Existen además otros tipos que aparecen en mucha menor proporción: uniseridados, con enrollamiento planoespiral, dicocíclicos, etc.

- Otros fragmentos fósiles identificados aunque en mucha menor proporción son: equinodermos, en muchos casos con cementación carbonatada sintaxial alrededor de bioclastos y bivalvos.

En función de todo lo anterior esta roca se puede clasificar como una biopelmicrita según criterios clasificatorios de FOLK o como una caliza "packstone" según los criterios de DUNHAM.

\section{Difracción de Rayos- $X$}

El difractograma de esta roca muestra las reflexiones características de la calcita y, a nivel de trazas, del cuarzo.

\section{Características químicas}

Los resultados evidencian una fracción silícea entre 1,0\% y $2,1 \%$, en tanto que la de carbonato cálcico entre $96 \%$ y $99 \%$. Los sulfatos oscilan entre $0,16 \%$ y $0,92 \%$, lo que puede deberse a la contaminación de la muestra con yeso procedente del recubrimiento.

\section{Contenido de sulfatos en las piedras}

Para determinar si las sales encontradas en las pátinas que recubren las piedras y morteros forman parte de su constitución 0 es un compuesto que se ha colocado sobre ellas, se ha procedido a tomar muestras a 2, 3 y 4 $\mathrm{cm}$ de profundidad.

Los resultados de los análisis oscilan entre $0,02 \%$ y 0,03\%, lo que permite afirmar que los sulfatos detectados en los

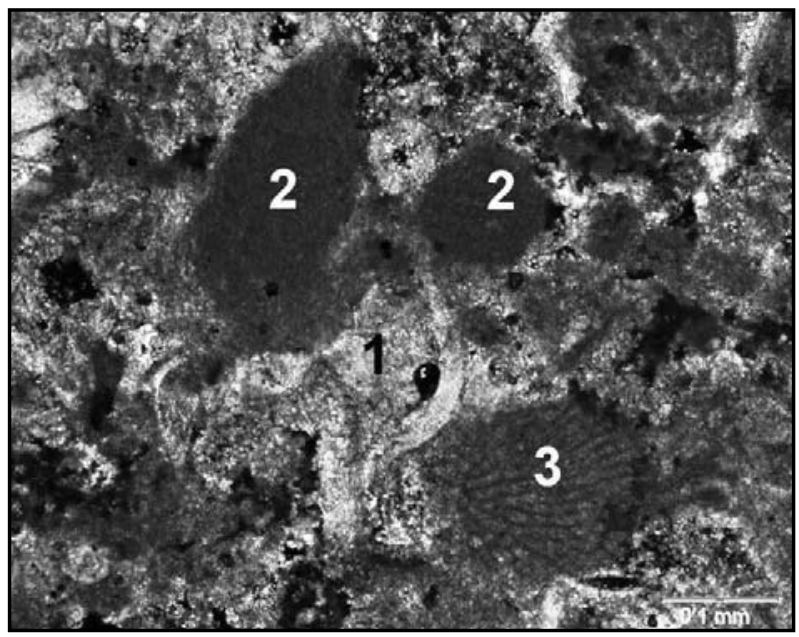

Figura 4b. Fango micrítico recristalizado (1) que engloba peloides micríticos bien redondeados (2) y fragmentos de algas coralinas (3). 
Tabla 3. Características físico-mecánicas de las piedras naturales

\begin{tabular}{|c|c|c|c|c|c|}
\hline Muestra & $\begin{array}{c}\text { Densidad } \\
\text { aparente gr/ c.c. }\end{array}$ & Porosidad \% & $\begin{array}{c}\text { Resistenci } \\
\text { MPa } \\
\text { En estado } \\
\text { seco }\end{array}$ & $\begin{array}{l}\text { compresión } \\
\text { En estado } \\
\text { saturado }\end{array}$ & $\begin{array}{l}\% \text { pérdida de } \\
\text { resistencia } \\
\text { al saturarse de agua }\end{array}$ \\
\hline$P-2$ & 2,38 & 6,9 & 39,7 & 30,9 & 22,2 \\
\hline P-3 & 2,21 & 10,1 & 23,1 & 13,8 & 40,3 \\
\hline P-4 & 2,26 & 8,5 & 34,4 & 20,9 & 33,4 \\
\hline
\end{tabular}

análisis de las piedras corresponden al recubrimiento dado a las mismas, y no a su composición.

\section{Estudio por ultrasonidos de las piedras}

Se ha utilizado el método indirecto colocando el emisor y receptor en la misma cara del elemento a ensayar, empleando en todas las medidas la misma distancia entre ambos $(10 \mathrm{~cm})$. Los resultados se expresan en forma de velocidad de paso del tren de ondas a través de la piedra.

La velocidad obtenida en los diferentes casetones de piedra oscila entre 2.522 y $3.165 \mathrm{~m} / \mathrm{seg}$., en tanto que la velocidad en los nervios oscila entre $1.988 \mathrm{~m} / \mathrm{seg}$. (en el que produjo la caída del fragmento) y $3.008 \mathrm{~m} / \mathrm{seg}$. Esto indica una gran heterogeneidad debido posiblemente a la existencia de diferentes calidades de piedra, la presencia de juntas, los recubrimientos de estuco, yeso y pintura, etc.

\section{Características hídricas}

Absorción-desorción de agua: como se observa en los gráficos de las figuras 5 y 6 , el proceso de absorción es rápido (24-48 horas) con porcentajes que oscilan entre $3,53 \%$ y $4,81 \%$. Por el contrario, la desorción es algo más lenta, ya que la pérdida total del agua absorbida se produce a las 72 horas.

Capilaridad (tiempo de ascensión capilar): la ascensión capilar de las tres muestras es alta, ya que a las 7-9 horas el agua ha alcanzado la altura máxima de la probeta.

\subsubsection{Recubrimientos}

Se han tomado muestras de las pátinas o recubrimientos raspando con escarpelo la superficie de diversas piedras. Los resultados de los análisis y ensayos efectuados son los siguientes:

\section{Descripción macroscópica}

Masa carbonatada y de yeso homogénea pero totalmente descohesionada, donde no es posible distinguir ningún grano silíceo, ni siquiera con ayuda de la lupa binocular.

\section{Difracción de Rayos- $X$}

El espectro obtenido mediante esta técnica indica la presencia de calcita como mineral principal y de yeso, la fracción de dolomita y cuarzo es a nivel de trazas. En consecuencia, se trata de restos de recubrimientos yesíferos contaminados con la roca soporte.
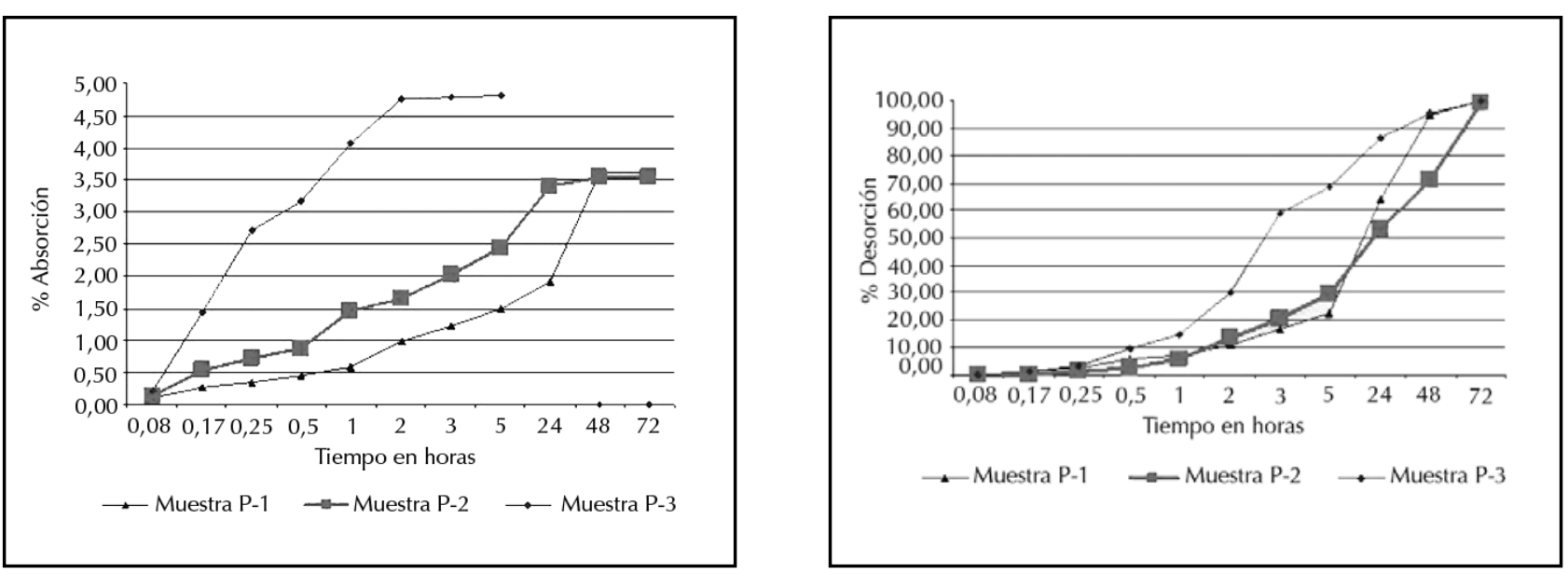

Figura 5 y 6 . Gráficos absorción-desorción de agua de las piedras. 


\section{Composición de los recubrimientos y pinturas}

A las muestras tomadas de las pinturas y recubrimientos se les han realizado los análisis y ensayos habituales de la pintura artística (12 y 13). Las muestras tomadas se clasificaron en grupos según la tonalidad ocre o dorada. El análisis se realizó mediante microscopía óptica con luz reflejada 300 x y 150 x. Los resultados son los que siguen:

Ocre: se ha comprobado que este revestimiento corresponde a un grueso estuco de calcita aplicado en dos capas. La inferior es blanca y contiene esencialmente calcita y un $15 \%$ aproximadamente de árido silíceo, esencialmente granos de cuarzo de entre 5 y $150 \mu$ de grosor. La capa superior es un estuco igual pero con granos de blanco de plomo añadidos, e impregnada posteriormente con aceite de linaza a modo de imprimación, lo que hace que adquiera un color pardo. Sobre ella hay dos capas de pintura al óleo.

Dorado: sobre el mortero o estuco de cal impregnado con aceite está una gruesa base de color rojo con tierras y un dorado al mixtión con asiento de tierras al óleo de aceite de linaza. Ese tipo de capas rojas al óleo aparece en la pintura en los siglos XVII y XVIII.

Ocre más claro: en este revestimiento el mortero es mucho más rico en cuarzo, la proporción de calcita es del 50\%. Los granos de cuarzo pueden llegar a las 400$500 \mu \mathrm{m}$. No obstante, se trata de una heterogeneidad que hay que explicar dentro de la normal variedad de materiales que estaban usando en el taller que hace que no todas las masas de mortero se hicieran con la misma arena. La pintura, como vemos, es casi igual que la primera.

Puede concluirse por tanto que el recubrimiento corresponde a pinturas al óleo sobre estuco-mortero de calcita, cuarzo, yeso y algo de blanco de plomo, con impregnación de aceite de linaza. Sobre la impregnación se aplican colores rojos y amarillos-ocre al óleo de aceite de linaza y dorados al mixtión.

\section{CONCLUSIONES}

La investigación realizada permite definir las fábricas de la Sala Capitular del Ayuntamiento de Sevilla como muros de piedra conformados por sillares de caliza "packstone" tomados con morteros de cal y arena. Las determinaciones físicas, mecánicas, químicas e hídricas de estos materiales indican que estas fábricas no tienen revestimiento de ningún tipo y que no hay barrera para la tensión de vapor no presentando alteraciones ni la piedra ni el mortero.

La bóveda-artesonado de este conjunto corresponde a un entramado de 36 casetones, con sus correspondientes nervios y relieves ejecutada con piezas labradas de piedra caliza tomadas con mortero de cal y arena, de forma similar a la de los muros. No obstante, hay diferencias notables con los muros, como es el revestimiento realizado a base de pinturas al óleo sobre estuco-mortero de calcita, cuarzo, yeso y presencia de blanco de plomo con impregnación de aceite de linaza, sobre la que aplicaron diversos colores, rojos, dorados, amarillos-ocres, como se deduce de la investigación realizada. Esta terminación actúa como una capa impermeable como queda demostrado con los datos de índice de humedad superficiales que en todas las determinaciones realizadas dan un índice de 0 en tanto que en el interior de la piedra oscilan entre 28 y 80 . Otro dato a tener en cuenta es el incremento de humedad ambiental que se produce en la bóveda, en torno al $72,1 \%$, y de la temperatura con un aumento del $20,1 \%$, consecuencia de la instalación de climatización.

Con estos antecedentes, la difusión del vapor de agua del interior de la piedra al exterior no se produce al existir la barrera impermeable del revestimiento, que no había generado daños en las fábricas hasta los últimos diez años en que se han producido desprendimientos de partículas del mortero y piedra y un fragmento apreciable de uno de los nervios. En este tiempo se ha producido un cambio ambiental significativo generado al pasarse de un recinto abierto a otro cerrado, con lo que ha desaparecido la ventilación cruzada y, lo más decisivo, la elevada concentración de humedad que se genera en la bóveda al haberse climatizado el recinto de la sala. Esta circunstancia puede producir una fuerte presión que es la que genera las anomalías descritas.

Puede concluirse, por tanto, que resulta fundamental conocer las características de los muros y de sus componentes, de los posibles tratamientos recibidos, y de las condiciones ambientales de humedad y temperatura, así como los cambios que pueden producirse con la instalación de climatización, y de cualquier otro cambio ambiental, con el fin de no modificar el equilibrio existente y generar en consecuencia lesiones y daños no previstos.

\section{AGRADECIMIENTOS}

Al Excmo. Ayuntamiento de Sevilla, por haber financiado esta investigación, y a la empresa VORSEVI S.A., por su colaboración. 


\section{BIBLIOGRAFÍA / BIBLIOGRAPHY}

(1) Monjo Carrió, J. et al.: Patología y técnicas de intervención fachadas y cubiertas. Ed. Murilla-Leria, 1999.

(2) Gestoso y Pérez, J.: Sevilla monumental y artística. 3 Volúmenes, 1889-1892.

(3) Morales Alfredo, J.: El Ayuntamiento de Sevilla. Arquitectura y Simbología, Sevilla, 1981.

(4) Martín Pérez, A.: Ensayos y experiencia de alteración en la conservación de obras de piedra de interés histórico artístico, Fundación Ramón Areces, 1990.

(5) Lubelli, Barbara; Van Hees, Rob P. J.; Groot, Caspar W. P.: Investigation on the behaviour of a restoration plaster aplied on heavy salt loaded masonry, Construction and Building Materials, 20 (2006), pp. 691-699.

(6) Blanco Varela, M. T. et al.: "Los revocos de Medina Azahara. Parte 1: Caracterización del material y procesos de alteración", Materiales de Construcción, № 245 (1997).

(7) Pérez Bernal, J. L.; Bello López, M. A.: Dióxido de azufre. Química atmosférica y destrucción del Patrimonio, Fundación El Monte, 2004.

(8) AA. VV.: Técnicas de diagnóstico aplicadas a la conservación de los materiales de construcción en los edificios históricos, Junta de Andalucía, IAPH, 1996.

(9) González, V. et al.: Análisis y ensayos a piedras y morteros, Vorsevi, 2005.

(10) Hardy, R.; Tucker, M.: "X-Ray powder diffraction of sediments" en Techniques in sedimentology. Scientific Publications, 1989.

(11) Parra, E.: Análisis y ensayos a pátinas, Universidad Alfonso X el Sabio, 2005.

(12) Álvarez de Buergo, M.; Fort, R.: "Protective patinas applied on stony façades of historical buildings in the past", Construction and Building Materials, 17 (2003), pp. 83-89.

(13) Palomo, A. et al.: "Pinturas rupestres de la cueva de La Graja. Caracterización de pigmentos y análisis digital de imágenes", Materiales de Construcción, № 273 (2004). 